\title{
The Impact of Individual Motivational Interview Based on Self-Care and Efficacy of Type 2 Diabetic Patients
}

\author{
Seyyed Sajjad Safari ${ }^{1}$, Mozhgan Rahnama², Abdolghani Abdollahimohammad³, Mahin Naderifar ${ }^{4}$ \\ ${ }^{1}$ Department of Nursing, Committee, Nursing and Midwifery School, Zabol University of Medical Sciences, Zabol, Iran. \\ ${ }^{2}$ Department of Nursing, Zabol University of Medical Science, Zabol, Iran. ${ }^{3}$ Department of Nursing, Medical Surgical \\ Faculty, Zabol University of Medical Sciences, Zabol, Iran. ${ }^{4}$ Department of Nursing, Faculty of Nursing and Midwifery, \\ Zabol University of Medical Sciences, Zabol, Iran.
}

\section{ABSTRACT}

\section{BACKGROUND}

The important factor to control diabetes is self-care behaviours and one of the necessary factors affecting self-care behaviours in diabetic patients is self-efficacy. The current study aimed to determine the impact of individual motivational interview based on self-care on self-efficacy of type 2 diabetic patients hospitalized in Nabi Akram hospital in Zahedan in 2018.

\section{METHODS}

In this randomized controlled clinical trial study, 40 diabetic patients were selected and randomly divided into intervention and control groups, where either group included 20 patients. Data collection tools utilized for this study were demographic questionnaire and Shere et al.'s self-efficacy questionnaire. The intervention group received 4 sessions of self-care motivational interview training individually and control group received the same training content during 4 sessions in the usual face-to-face manner and without applying the principles of motivational interview. 8 weeks after the intervention terminated, self-efficacy was measured in both groups. Then, the gathered data were analysed through Shapiro-Wilk statistical test, independent t-test, and covariance analysis using SPSS Ver. 23.

\section{RESULTS}

After the intervention, the mean score of self-efficacy of diabetic patients in the intervention group (47.27 7. 7.33) was significantly higher than the mean score of the control group (41.22 4.4.74). ( $\mathrm{p}<.001)$

\section{CONCLUSIONS}

Motivational interview training based on self-care has positive impact on selfefficacy of type 2 diabetic patients. Therefore, the nurses are suggested to apply the principles of motivational interview while training these patients.

\section{KEY WORDS}

Motivational Interview, Self-Care, Self-Efficacy, Type 2 Diabetes
Corresponding Author:

Mozhgan Rahnama,

Department of Nursing,

Zabol University of Medical Science,

Zabol, Iran.

E-mail: jahant1990@gmail.com

DOI: 10.14260/jemds/2019/749

Financial or Other Competing Interests: None.

How to Cite This Article:

Safari SS, Rahnama $M$, Abdollahimohammad $A$, et al. The impact of individual motivational interview based on self-care and efficacy of type 2 diabetic patients. J. Evolution Med. Dent. Sci. 2019;8(46):3459-3463, $10.14260 /$ jemds/2019/749

Submission 24-09-2019,

Peer Review 31-10-2019,

Acceptance 06-11-2019,

Published 18-11-2019. 


\section{BACKGROUND}

In Iran, more than 3 million people are suffering from diabetes and according to World Health Organization estimates, if no effective measures are taken, this number will reach 7 million by 2030.(1) Diabetes is associated with increasing the risk of cardiovascular and renal diseases and therefore cause death in diabetic people 2 to 3 times more than the healthy people. (2) This disease alone caused 4.9 million death worldwide in 2014 and therefore, one of the most important leading causes of death in diabetic people is not carrying out self-care.(3) Diabetic patients, who have less ability to carry out self-care, are more likely to develop the complications of this disease,(4) and one of the reasons for failure to achieve optimal treatment outcomes in diabetic patients is the lack of patients' participation in diabetic treatment(2) because diabetic patients are responsible for taking care and treating their disease.(5) Self-care includes following a healthy diet, self-monitoring blood sugar or urine, doing regular physical activities and taking care of feet.(4) Self-efficacy in diabetes; however, predicts willingness to change and decision to do interventions relevant to selfcare.(6) Self-efficacy is attributed to the individual's beliefs and judgments in his/her abilities in doing duties and responsibilities(5) and several studies show that higher selfefficacy is associated with improving self-care behaviours. $(7,8,9,10,11)$ Given that the available evidence indicate that there is an undesirable level of self-care behaviours among diabetic patients and this issue results in failure in the offered training $\operatorname{programs}^{(12)}$ and since improving self-efficacy is of much importance in the process of changing behaviour,(13) using motivational interview, which is a strategy for changing the behaviour of patientoriented and its purpose is identifying and reducing patients' hesitation about changing health behaviours and improving the patients' perceptions of the importance of changing behaviour and self-efficacy, is suggested.(14) Motivational interview increases motivation, attract the individual's attention to the issue, and causes the bigger changes to be made.(15) Motivational interview can be offered as a single intervention or can be used for the purpose of generating motivation before the other treatment. Considering the special nature diabetes, it seems that motivational interview is one of the interventions which can be used to reduce serious complications of this prevalent disease.(16) The current study aimed to determine the impact of training individual motivational interview based on self-care on selfefficacy of type 2 diabetic patients.

\section{METHODS}

The current research is randomized controlled clinical trial study. The aim of this research was determining the impact of training individual motivational interviewing based on selfcare on self-efficacy of type 2 diabetic patients. The statistical population of this research consisted of all type 2 diabetic patients hospitalized in Nabi Akram (pbuh) hospital of Zahedan in 2018. Considering that the criteria for selecting sample such as definitive diagnosis of diabetes by a specialist, having literacy, not having other chronic illnesses other than diabetes, no pregnancy and not having previous experience in motivational interviewing, 40 patients based on similar study, who stated their willingness to participate in this study, were selected by convenience sampling method. First all patient's lists were taken from the related hospitals, those that had entrance criteria were distinguished. Then, they were divided into intervention (20 patients) and control groups (20 patients) based on simple random method using table of random numbers. The sample size was estimated based on Dehghani's study(17) and statistical formula for means difference.(18) Besides, the confidence interval and power of statistics were set at $95 \%$ and $80 \%$, respectively. Concerning the possibility of attrition, sample size was increased to 20 for each group (40 in total).Two questionnaires were used as data collection tools: 1 . Researcher-made demographic questionnaire included 16 questions to collect data about gender, place of residence, marital status, educational and occupational status, the persons who live with the participant, suffering from diabetic complications and receiving previous training relevant to diabetic self-care. 2. Sherer et al.'s (1982) general self-efficacy questionnaire included 17 items. For each item on this scale, there are 5 responses based on Likert-type scale. These responses, which include strongly disagree, disagree, neutral, agree, and strongly agree, receive scores from 1 to 5 . However, items of 9, 8, 3, 1, 13, and 15 achieve scores of 5 to 1 , respectively, and the other items, i.e., $2,4,5,6,7,10,11,12$, 14,16 , and 17 achieve scores of 1 to 5 , respectively. Thus, the highest score of self-efficacy in this scale is 85 and the lowest score is 17 . Higher scores indicate stronger self-efficacy and lower scores represent weaker self-efficacy. For estimating reliability of general self-efficacy questionnaire, Sherer et al. (1982) used Cronbach's alpha and achieved 0.76 for it. The validity of this scale has been achieved through construct validity.(19) The reliability of Sherer et al.' general self-efficacy questionnaire for the current study was obtained as $0.90 \%$ using Cronbach's alpha and Jahanimaleki et al. (1390) determined its reliability $0.74 \%$ through using Cronbach's alpha.(19)

Ethical considerations were taken into account in this study, that is to say, written consent was obtained from research units after providing clear explanations about the purposes of the study and its methodology and also reassuring them about the confidentiality of their information and their freedom to exit from the study at any stage. At the beginning of the intervention, the demographic and Sherer's self-efficacy questionnaires were first completed by each patient under careful supervision of the researcher. Then, the intervention group received 4 sessions of training plan for self-care behaviours using the principles motivational interviewing. This training plan was offered individually during 4 days at the patient's bedside and based on the determined content, on the last day of hospitalization. The training content relevant to self-care was prepared using sources and relevant guidelines in the form of 4 forty-minute sessions of speech and question and response and self-care contents were offered using the principles and fundamentals of motivational interviewing at each of the quadruple sessions, which this is indicated in table 1 at the bottom of the content of each session (Table 1). 8 weeks after the discharge of each patient, the researcher went to each patient's home in order that the patient complete Sherer's self-efficacy 
questionnaire as a post-test again. The control group received the usual self-care training plan during 4 forty-minute and face-to-face individual training sessions based on the selfcare training content specified in table 1 and without applying the principles of motivational interviewing. Also, post-test was performed at the same time interval (8 weeks). Intervention was offered in both groups by master of psychiatric nursing.(20)

\begin{tabular}{|c|c|}
\hline Session & Training Content \\
\hline First & $\begin{array}{c}\text { Familiarity and introduction, disease review, definitions, reasons, } \\
\text { disease progress. } \\
\text { The principles of motivational interviewing: the practice of identifying } \\
\text { and labelling emotions, the practice of impact of non-observing self-care } \\
\text { behaviours on different aspects of life. }\end{array}$ \\
\hline Second & $\begin{array}{c}\text { The importance of self-care, observing diet, regular exercise, taking care } \\
\text { of feet. } \\
\text { The principles of motivational interviewing: the assessment of short- } \\
\text { term and long-term profits and losses, non-observing self-care } \\
\text { behaviours and the practice of balancing decision making, describing } \\
\text { one day of daily life. }\end{array}$ \\
\hline Third & $\begin{array}{c}\text { Correct and timely insulin injection, identifying symptoms of increasing } \\
\text { and decreasing blood glucose, regular drug use. } \\
\text { The principles of motivational interviewing: the practice of identifying } \\
\text { values and creating cognitive contradiction in order to generate intrinsic } \\
\text { motivation. }\end{array}$ \\
\hline Fourth & $\begin{array}{l}\text { Increasing the quality of life, question and answer about discussed } \\
\text { topics and conclusion. } \\
\text { The principles of motivational interviewing for the intervention group: } \\
\text { the horizon of vision, recognizing tempting situations and controlling } \\
\text { and lack of controlling behaviour in those situations, offering rewards } \\
\text { for accomplishments, reinforcing self-efficacy. }\end{array}$ \\
\hline & ructure of Sessions and the Content of Training Self-Care \\
\hline
\end{tabular}

\section{Ethical Consideration}

The protocol of the present study was approved by Institutional review board and Ethics Committee of University of Zabol University of Medical science (Ethic code: IR.ZBMU.REC.1397.148). Written and oral informed consents were obtained from all participants.

\section{Statistical Analysis}

The collected data were analyzed by SPSS software (Version 23). The frequency, percentage, mean, and standard deviation were determined using descriptive statistics. Independent ttest was used to calculate the mean scores pre- and postintervention between two intervention and control groups. Analysis of covariance was used to determine the impact of motivational interviewing by controlling pre-test scores. ChiSquire test was used to find out differences in demographic profile. The significance level in this study was assumed to be 0.05 .

\section{RESULTS}

Investigation of individual characteristics of research units indicates that the majority of persons included in intervention (55) and control (60) groups were female and male, respectively. Considering the place of residence of two groups, the majority of them (more than 70\%) lived in Zahedan. Concerning marital status of two groups, all of them were married. With regard to their educational status, both of groups had literacy (50\% of intervention group and $45 \%$ of control group). Regarding their employment status, the majority of persons involved in intervention group were housekeeper (55\%) and the majority of persons in control group were retired (40\%) and housekeeper (40\%). The majority of persons in both of groups lived their spouses and children (80\% of intervention group and 65\% of control group) and they were suffering from diabetic complications ( $60 \%$ of intervention group and $75 \%$ of control group). Also, $70 \%$ of persons in intervention group and $60 \%$ of persons in control group did not receive training relevant to diabetes. These two groups were similar in terms of all of these variables. The average duration of suffering from diabetes and the average duration of treatment for intervention and control groups were $3,4,4$ and 5, 7, 4 years, respectively. Furthermore, there was no statistically significant difference between these two groups in terms of the mean of these two variables and these two groups were similar in terms of two variables of duration of suffering and treatment.

\begin{tabular}{|c|c|c|c|c|}
\hline \multirow{2}{*}{\multicolumn{2}{|c|}{ Variable }} & \multicolumn{2}{|c|}{ Frequency (\%) } & \multirow[b]{2}{*}{$\begin{array}{c}\text { Chi- } \\
\text { Square }\end{array}$} \\
\hline & & \multirow{2}{*}{$\begin{array}{c}\text { Control } \\
\text { Group } \\
12(60) \\
\end{array}$} & \multirow{3}{*}{$\begin{array}{c}\begin{array}{c}\text { Intervention } \\
\text { Group }\end{array} \\
9(45) \\
11(55)\end{array}$} & \\
\hline \multirow{2}{*}{ Gender } & male & & & \multirow{2}{*}{.342} \\
\hline & female & $8(40)$ & & \\
\hline \multirow{2}{*}{ Address } & Zahedan & $15(75)$ & $14(70)$ & \multirow{2}{*}{.723} \\
\hline & Suburb of Zahedan & $5(25)$ & $6(30)$ & \\
\hline \multirow{2}{*}{ Marital status } & Single & $0(0)$ & $0(0)$ & \\
\hline & Married & $20(100)$ & $20(100)$ & \\
\hline \multirow{4}{*}{$\begin{array}{l}\text { Academic } \\
\text { status }\end{array}$} & Literacy & $9(45)$ & $10(50)$ & \multirow{4}{*}{.623} \\
\hline & Fifth grade & $5(25)$ & $6(30)$ & \\
\hline & Middle school & $1(5)$ & $2(10)$ & \\
\hline & Diploma and higher & $5(25)$ & $2(10)$ & \\
\hline \multirow{5}{*}{$\begin{array}{l}\text { Employment } \\
\text { status }\end{array}$} & Employee & $2(10)$ & $1(5)$ & \multirow{5}{*}{.193} \\
\hline & Retired & $8(40)$ & $3(15)$ & \\
\hline & Self-employment & $0) 0)$ & $3(15)$ & \\
\hline & Housekeeper & $8(40)$ & $11(55)$ & \\
\hline & Unemployed & $2(10)$ & $2(10)$ & \\
\hline \multirow{4}{*}{$\begin{array}{l}\text { Who do you } \\
\text { live with }\end{array}$} & Spouse & $4(20)$ & $2(10)$ & \multirow{4}{*}{.727} \\
\hline & $\begin{array}{l}\text { Spouse along with } \\
\text { children }\end{array}$ & $13(65)$ & $16(80)$ & \\
\hline & Children & $1(5)$ & 1(5) & \\
\hline & I live alone & $2(10)$ & $1(5)$ & \\
\hline \multirow{2}{*}{$\begin{array}{c}\text { Do you have } \\
\text { diabetic } \\
\text { complications }\end{array}$} & Yes & $15(75)$ & $12(60)$ & \multirow[b]{2}{*}{.311} \\
\hline & No & $5(25)$ & $8(40)$ & \\
\hline \multirow{2}{*}{$\begin{array}{l}\text { Training } \\
\text { relevant to } \\
\text { diabetes }\end{array}$} & Yes & $8(40)$ & $6(30)$ & \multirow[b]{2}{*}{.507} \\
\hline & No & $12(60)$ & $14(70)$ & \\
\hline
\end{tabular}

As it is clear from Table 3, the findings relevant to the major goal of this study indicated that by controlling confounding impact of pre-test scores, analysis of covariance revealed that the mean total score of self-efficacy of intervention group is higher than that of control group, representing that training individual motivational interviewing based on self-care has positive impact on selfefficacy of type 2 diabetic patients than the usual face-to-face training which does not apply the principles of motivational interviewing.

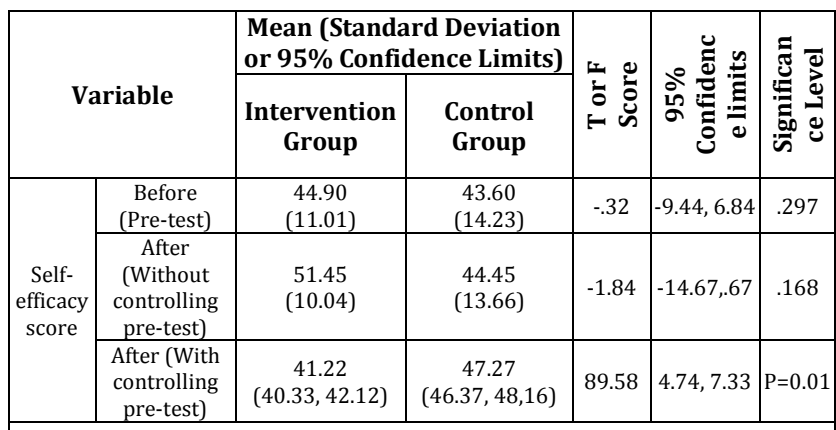

Table 3. Comparison of the Mean Scores of Self-Efficacy in Two Control and Intervention Groups after Controlling Pre-Test 


\section{DISCUSSION}

The results of the current study indicated the positive impact of training individual motivational interviewing based on self-care than training usual face-to-face motivational interviewing which does not apply the principles of motivational interviewing on self-efficacy of diabetic type 2 patients In this section, the results of this study will be discussed. It is worth mentioning that since self-efficacy is the important and basic precondition to successful conduct selfcare behaviours(12) and a variety of studies have demonstrated a positive and meaningful correlation between self-efficacy and self-care, $(10,12,7,11)$ independent variable in some studies which have been used for the comparison, are self-management or self-care of diabetes and the factors relevant to them such as blood glucose levels, physical activity and so on.

In the current study, self-efficacy of type 2 diabetic patients, who had received the training of self-care based on the principles of motivational interviewing, was higher than the patients who had not received the same training which does not use these principles. Conducting a study aimed to determine the impact of group motivational interviewing and cognitive-behavioural group training on biological indices, life quality, taking care of self and physical health indices (weight loss and blood glucose control) of type 2 diabetic patients, Poursharifi concluded that group motivational interviewing compared to cognitive-behavioural group training, can better improve self-care in the areas of exercise and blood glucose control.(16 and 21) As a result, this study is in accordance with the current study. Although in this study contrary to that of Poursharifi, motivational interviewing was presented as a group, it has been found to be a good comparison to use this study because it suggests the superiority of motivational interviewing based on another teaching method in type 2 diabetic patients. The positive impact of training motivational interviewing based on selfcare on self-efficacy of type 2 diabetic patients of the current study is possibly due to increasing motivation of these patients to carry out self-care following receiving training based on the principles of motivational interview. In line with this, Morowati Sharifabad (1387) point outs that since selfefficacy is actually the belief and the expectation of person in his/her capacity to influence favorable consequence through individual efforts, it can be stated that self-efficacy influences motivation, and the stronger the beliefs are, the more active the person is and his/her effort increases and his/her persistence in attaining a specific goal will be more.(14)

The researcher in his launched searches found many studies such as Chen (2012), which were in line with the current study in terms of their results. Chen (2012) in his study discovered that motivational interviewing had positive impact on the management of self-efficacy of diabetic patients.(22) Chelbowy (2015) also reported that the results of using motivational interviewing as an intervention to advance the health outcomes of diabetic patients and their adherence to therapeutic diets was positive. ${ }^{(23)}$ Furthermore, Racic (2015) in his study about treatment consequences and Song (2014) in his study related to self-management of type 2 diabetic patients reported the positive impacts of motivational interviewing.(24 and 25)
Moreover, Davern Soderlund (2018) conducted a review study about the effectiveness of motivational interviewing in advancing self-management physical activities of type 2 diabetic patients. In conclusion, he revealed that out of 9 final papers contained the intended criteria, 4 papers accentuated the meaningful impacts resulted from interventions of motivational interviewing on results of physical activity of these patients.(26)In addition, Dellasega et al. (2010) in their study emphasized that motivational interviewing is a useful and vital technique which can be used by nurses in training and taking care of type 2 diabetic patients.(27) Therefore, all of these studies align with the results of the current study.

On the other hand, the researcher in his launched searches also found studies which were not in line with this study. For example, Ghahremani (1396) stated that conducting motivational interviewing based on self-efficacy did not show positive impact on the laboratory results (Blood glucose, cholesterol, triglyceride and glycated haemoglobin) of type 2 diabetes patients.(15) Welch et al. (2011) indicated that in their type 2 diabetes patients, offering motivational interviewing along with training diabetes's self-management had less impact than training diabetes's self-management alone.(14) Differences in the research environment, the way the training is provided, and even cultural factors have possibly contributed to these different outcomes. In line with this finding, Shabibi et al. (1395) point out that the extent of observing and exhibiting self-care behaviours varies according to different cultural contexts. (4)

The limitations on the researcher in this study were the trainings relevant to self-care which derived from other sources such as books, radio and television by the patients during training self-care plan, psychological factors affecting these patients and inability to perform long-term follow-up intervention impacts and persistence of training. In fact, these limitations were beyond the researcher's control.

\section{CONCLUSIONS}

Training individuals with motivational interviewing based on self-care can possibly increase these patients' self-efficacy by increasing type 2 diabetic patients' motivation. Particularly, the majority of conducted studies in this regard, showed accentuation of the positive impact of motivational interviewing on the treatment consequences and also on taking care of diabetic patients. Therefore, training individuals with motivational interviewing based on self-care as a nursing intervention in these patients is suggested.

\section{ACKNOWLEDGEMENT}

This article is the result of the thesis of a Master of Science in Internal Surgery from Nursing School of Zabol University of Medical Sciences with Code of Ethics IR.ZBMU.REC.1397.148. The authors of this article would like to thank Zabol University of Medical Sciences and the patients who participated in the study and all those who helped us to carry out this study. 


\section{REFERENCES}

[1] Taheri Z, Khorsandi M, Taheri Z, et al. Empowerment based interventions in patients with diabetes: a review study. J Rafsanjan Univ Med Sci 2016;15(5):453-68. (In Persian)

[2] Jalilian F, Motlagh FZ, Solhi M. Effectiveness of education program on increasing self- management among patients with type 2 diabetes. Scientific Journal of Ilam University of Medical Sciences 2012;20(1):26-34. (In Persian)

[3] Hejazi S, Peyman N, Tajfard M, et al. The impact of education based on self-efficacy theory on health literacy, self-efficacy and self-care behaviours in patients with type 2 diabetes. Iranian Journal of Health Education and Health Promotion 2018;5(4):296-303. (In Persian)

[4] Shabibi P, Mansourian M, Abedzadeh MS, et al. The status of self-care behaviours in patients with type 2 diabetes in the city of Ilam in 2014. Scientific Journal of Ilam University of Medical Sciences 2015;24(2):163-71. (In Persian)

[5] Mazloomi SS, Mody M, MalkiMoghadam H, et al. Predictors of self-care in type 2 diabetic patients in Birjand and Yazd city. Iranian Journal of Diabetes and Metabolism 2018;17(2):97-104. (In Persian)

[6] Mishali M, Omer H, Heymann AD. The importance of measuring self-efficacy in patients with diabetes. Family Practice 2011;28(1):82-7.

[7] Masoompour M, Tirgari B, Ghazanfari Z. The relationship between health literacy, self-efficacy and self-care behaviours in diabetic patients. Evidence Based Care Journal 2017;7(3):17-25.

[8] Walker RJ, Smalls BL, Hernandez-Tejada MA, et al. Effect of diabetes self-efficacy on glycemic control, medication adherence, self-care behaviours and quality of life in a predominantly low-income, minority population. Ethnicity \& Disease 2014;24(3):349-55.

[9] Boogar ER, Besharat MA, Tehrani MM, et al. Predictive role of self- efficacy, belief of treatment effectiveness and social support in diabetes mellitus self- management. Iranian Journal of Psychiatry and Clinical Psychology 2011;17(3):232-40. (In Persian)

[10] Shakibazadeh E, Rashidian A, Larijani B, et al. Perceived barriers and self- efficacy: impact on self- care behaviours in adults with type 2 diabetes. Journal of Hayat 2010;15(4):69-78. (In Persian)

[11] Karimi M, Koohestani HR, Araban M. The association between attitude, self- efficacy and social support and adherence to diabetes self- care behaviour. Diabetology \& Metabolic Syndrome 2018;10(86).

[12] Vazini H, Barati M. Predicting factors related to self- care behaviours among type 2 diabetic patients based on health belief model. Journal of Torbat Heydarieh University of Medical Sciences 2014;1(4):16-25. (In Persian)

[13] Morowatisharifabad M, Tonekaboni NR. Perceived selfefficacy in self- care behaviours among diabetic patients referring to Yazd Diabetes Research Center. Journal of Birjand University of Medical Sciences 2008;15(4):91-9. (In Persian)

[14] Welch G, Zagarins SE, Feinberg RG, et al. Motivational interviewing delivered by diabetes educators: Dose it improve blood glucose control among poorly controlled type 2 diabetes patients. Diabetes Res Clin Prac 2011;91(1):54-60.

[15] Ghahremani A, Alinejad V, Pak HMM. Effect of selfefficacy-based motivational interview on laboratory results in type 2 diabetes. The J Urmia Nurs Midwifery Fac 2017;15(9):688-95. (In Persian)

[16] Poursharifi H, Zamani R, Mahyar AH, et al. The effectiveness of motivational interviewing in improving the outcomes of well- being, quality of life and self- care in adults with type 2 diabetes. Journal of Modern Psychological Research 2011;6(23):39-60. (In Persian)

[17] Dehghani FS, Ghasemi H, Safari S, et al. The effectiveness of group MI sessions on enhancing of addicted women's self- esteem and self- efficacy. Quarterly Journal of Research on Addiction 2013;7(26):145-58. (In Persian)

[18] Abdollahimohammad A, Firouzkouhi M. Sample size estimation in randomized clinical trials (RCTs). J Diabetes Nurs 2019;7(1):737-9. (In Persian)

[19] Maleki JS, Sharifi M, Maleki JR, et al. The relationship between awareness levels of life skill with self- efficacy beliefs among Shahid Beheshti University students. Journal of Modern Psychological Research 2011;6(22):19-49. (In Persian)

[20] Navidian A, Mobaraki H, Shakiba M. Efficacy of Motivational Interviewing on Self-efficacy in Patients with Heart Failure and Depression. Journal of Mazandaran University of Medical Sciences 2017;27(155:46-59. (In Persian)

[21] Poursharifi H, Zamani R, MahyarA-H, et al. The effectiveness of motivational interviewing on improving physical health outcomes (weight loss and glycogenic control) in adults with type 2 diabetes. Contemporary Psycholigy 2008;3(2):1-14. (In Persian)

[22] Chen SM, Creedy D, Lin HS, et al. Effects of motivational interviewing intervention on self- management, psychological and glysemic outcomes in type 2 diabetes: a randomized controlled trial. Int J Nurs Stud 2012;49(6):637-44.

[23] Chelbowy DO, El Mallakh P, Myers J, et al. Motivational interviewing to improve diabetes outcomes in African American adults with diabetes. Western Journal of Nursing Research 2015;37(5):566-80.

[24] Racic M, Katic B, Joksimovic BN, et al. Impact of motivational interviewing on treatment outcomes in patients with diabetes type 2: a randomized controlled trial. Journal of Family Medicine 2015;2(1):01-06.

[25] Song D, Xu TZ, Sun QH. Effect of motivational interviewing on self- management in patients with type 2 diabetes mellitus: a meta-analysis. International Journal of Nursing Sciences 2014;1(3):291-7.

[26] Soderlund DP. Effectiveness of motivational interviewing for improving physical activity self-management for adults with type 2 diabetes: a review. Chronic Illness 2018;14(1):54-68.

[27] Dellasega Ch, Gabbay R, Durdock K, et al. Motivational interviewing (MI) to change type 2DM self- care behaviours: a nursing intervention. J Diabetes Nurs 2010;14(3):112-18. 